DOI: $10.5216 /$ cab.v13i4.14105

\title{
INDICADORES BIOQUÍMICOS SÉRICOS E DO LÍQUIDO PERITONEAL DE EQUINOS SUBMETIDOS À OBSTRUÇÃO INTESTINAL
}

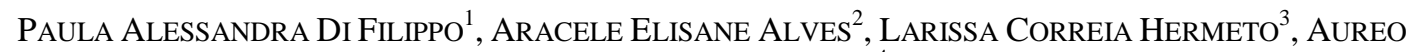 \\ EVANGELISTA SANTANA ${ }^{4}$ \\ ${ }^{1}$ Professora Doutora da Universidade Estadual do Norte Fluminense "Darcy Ribeiro", UENF, Campos dos Goytacazes, RJ, Brasil - \\ difilippo@uenf.br \\ ${ }^{2}$ Pós-doutoranda da Faculdade de Ciências Agrárias e Veterinárias FCAV/UNESP, Jaboticabal, SP, Brasil. \\ ${ }^{3}$ Doutoranda da FCAV/UNESP, Jaboticabal, SP, Brasil. \\ ${ }^{4}$ Professor Doutor da FCAV/UNESP, Jaboticabal, SP, Brasil.
}

\section{RESUMO}

Foram utilizados vinte e quatro equinos distribuídos em quatro grupos, controle instrumentado (GI), obstrução do duodeno (GII), do íleo (GIII) e do cólon maior (GIV). Amostras de sangue e de líquido peritoneal foram colhidas uma hora antes do procedimento cirúrgico (T0), ao final do período de três horas de obstrução (T3ob) e 1, 3, 12, 24, 120 e 168 horas após desobstrução (T1des-T168des), para determinação da atividade das enzimas aspartato aminotransferase, creatina quinase, lactato desidrogenase e fosfatase alcalina e da concentração de fósforo inorgânico e de lactato. Foram observadas alterações nas concentrações séricas e peritoneais das variáveis bioquímicas supramencionadas somente nos animais submetidos à obstrução de duodeno (GII) e de íleo (GIII). Entretanto, após três horas de obstrução só foram verificadas alterações nas concentrações peritoneais de lactato, lactato desidrogenase, fósforo inorgânico e de creatina quinase. A análise bioquímica do líquido peritoneal permitiu, quando comparada a sérica, o diagnóstico precoce de lesão entérica localizada no intestino delgado e, portanto, deve ser priorizada na avaliação pré-operatória do equino com cólica.

PALAVRAS-CHAVE: biomarcadores; cólica; equino.

\section{SERUM AND PERITONEAL FLUID BIOCHEMICAL MARKERS OF HORSES SUBMITTED TO INTESTINAL OBSTRUCTION}

\section{ABSTRACT}

Twenty-four horses were distributed into four different groups, instrumented control (GI), duodenum obstruction (GII), ileum obstruction (GIII) and large colon obstruction (GIV). Serum and peritoneal fluid analysis of aspartate aminotransferase, creatine kinase, lactate dehydrogenase, alkaline phosphatase, inorganic phosphorus and lactate were measured. Samples were collected one hour before the surgical procedure (T0); 3 hours after the obstruction (T3ob), 1, 3, 12, 24, 120 and 168 hours after the beginning of reperfusion/deobstruction. Duodenal (GII) and ileum
(GIII) obstructions changed serum and peritoneal fluid biochemical analysis. However, only lactate, lactate dehydrogenase, creatine kinase and inorganic phosphorus concentrations were abnormal in peritoneal fluid three hours after the obstruction. The biochemical analysis of peritoneal fluid allowed a faster diagnostic of intestinal alterations than the serum analysis; hence it should be prioritized when pre-operatory colic assessment is carried out.

KEYWORDS: biomarkers; colic; equine. 


\section{INTRODUÇÃO}

A síndrome cólica é responsável por $20 \%$ dos internamentos hospitalares em equinos, sendo considerada a maior causa de óbito nessa espécie. Não é uma entidade nosológica específica e sim um conjunto de múltiplas condições consequentes a determinadas disfunções de vísceras intraabdominais. Apesar dos avanços em relação aos métodos de diagnóstico, às técnicas anestésicas e cirúrgicas e ao acompanhamento intensivo no pósoperatório, a mortalidade permanece alta (THOEFNER et al., 2003).

Estima-se que, nos Estados Unidos, a mortalidade atinja $13 \%$ dos casos não submetidos à cirurgia e $31 \%$ nos casos que requerem intervenção cirúrgica (KANEENE et al., 1997). No Brasil, em ensaio realizado com 50 animais com cólica e submetidos à laparotomia, DI FILIPPO et al. (2010) verificaram que $27(54 \%)$ sobreviveram e $23(46 \%)$ foram a óbito ou sacrificados. Dentre os 27 sobreviventes, $21(78 \%)$ apresentavam lesões no intestino grosso (IG) e apenas seis $(22 \%)$ no intestino delgado (ID). Entretanto, dos 23 animais que foram a óbito ou sacrificados, $15(65,21 \%)$ apresentavam lesões no delgado e oito $(34,78 \%)$ no intestino grosso.

$\mathrm{Na}$ cólica, as alterações ocorridas nas alças intestinais repercutem diretamente na composição dos fluidos orgânicos, alterando-os na dependência do tempo, localização e gravidade do processo obstrutivo. Nessas condições, marcadores bioquímicos são permeáveis aos fluidos corporais, constituindo-se em indicadores sensíveis e específicos de degeneração intestinal (MOORE et al., 1998; SOUTHWOOD, 2006). As enzimas cujas concentrações são frequentemente determinadas na avaliação das lesões intestinais em equinos com cólica são a creatina quinase (CK), a aspartato aminotransferase (AST), a lactato desidrogenase (LDH) e a fosfatase alcalina (FROSCHER \& NAGODE, 1981; VALADÃO et al., 1996). Fósforo inorgânico e lactato também constituem-se em importantes marcadores (ARDEN \& STICK, 1988; SOUTHWOOD, 2006).

Diante dessas observações, o presente estudo visou avaliar as alterações nas concentrações de lactato, fósforo inorgânico e na atividade das enzimas CK, LDH, AST e FA no sangue e no líquido peritoneal de equinos submetidos à obstrução extraluminal do duodeno, íleo e cólon maior.

\section{MATERIAL E MÉTODOS}

Foram utilizados 24 equinos, oito fêmeas (não-gestantes), 16 machos (12 castrados e quatro não castrados), sem raça definida, com média de idade de 6,2 $\pm 3,0$ anos, escore corporal de três a quatro e peso corporal médio de $295,9 \pm 32,7 \mathrm{~kg}$. Uma semana antes do experimento, após avaliação clínica, fez-se o controle de endoparasitas (mebendazol ${ }^{1}$, $50 \mathrm{mg} \mathrm{kg}^{-1}$ ) e de ectoparasitas (deltametrina ${ }^{2}$ a $0,025 \%)$. Os animais foram mantidos em piquetes coletivos com dieta a base de feno de coast-cross (Cynodon dactylon) e água à vontade. A ração concentrada comercial ${ }^{3}$ foi fornecida duas vezes ao dia em quantidade equivalente a $1 \%$ do peso corpóreo $(2,5$ a $3,4 \mathrm{~kg})$, adicionada de $50 \mathrm{~g} / \mathrm{dia}$ de suplemento mineral ${ }^{4}$.

Os equinos foram separados em quatro grupos de seis animais (duas fêmeas, três machos castrados e um não castrado) - um grupo controle instrumentado - GI - (sem realização da obstrução intestinal, porém submetidos aos mesmos procedimentos anestésicos e cirúrgicos descritos para os animais dos demais grupos) e três grupos obstruídos. As obstruções intestinais foram realizadas em três diferentes segmentos: duodeno (GII), íleo (GIII) e cólon maior - flexura pélvica (GIV).

Os animais foram contidos em brete e, após tricotomia e antissepsia da fossa paralombar, foram sedados com acepromazina $1 \%{ }^{5}\left(0,025 \mathrm{mg} \mathrm{kg}^{-1}, \mathrm{IV}\right)$, cloridrato de xilazina $2 \%^{6}\left(0,5 \mathrm{mg} \mathrm{kg} \mathrm{kg}^{-1}\right.$, IV $) \mathrm{e}$ meperidina ${ }^{7}\left(4 \mathrm{mg} \mathrm{kg}^{-1}, \mathrm{IM}\right)$. Procedeu-se a anestesia local infiltrativa, utilizando-se associação (1:1) de lidocaína $2 \%^{8}$ e bupivacaína $0,75 \%^{9}$, ambas sem vasoconstritor. Visando mimetizar ao máximo as condições naturais, os animais não foram submetidos a jejum hídrico e alimentar prévios.

Com os animais em posição quadrupedal, por meio da laparotomia, flanco direito para duodeno e íleo e, esquerdo para cólon maior, os segmentos intestinais foram identificados e em seguida, um dreno de Penrose $\mathrm{n}^{\mathrm{0}} \mathbf{3}$ foi posicionado ao redor da alça intestinal e, após o seu completo fechamento, iniciou-se a obstrução intestinal, segundo modelo descrito por DATT \& USENIK (1975). Neste momento, os animais receberam $1,5 \mathrm{mg} \mathrm{kg}^{-1}$, IV de cloridrato de tramadol ${ }^{10}$. Sequencialmente, procedeuse a sutura simples contínua dos músculos transversos do abdômen e da pele, utilizando-se de vicryl $\mathrm{n}^{-2}$ e náilon $\mathrm{n}^{\mathrm{o}} 4$, respectivamente. As obstruções foram mantidas por três horas e, após

\footnotetext{
${ }^{1}$ Platelmin Eqüino - UCB S. A

${ }^{2}$ Butox P - Intervet S. A.

${ }^{3}$ Tec Horse - Purina.

${ }^{4}$ Omolen Ephos - Purina.

${ }^{5}$ Acepran $1 \%$ - Univet S. A

${ }^{6}$ Virbaxil 2\% - Virbac.

${ }^{7}$ Dolosal - Cristália.

${ }^{8}$ Lidovet - Bravet.

${ }^{9}$ Neocaína $0,75 \%$ - Cristália.

${ }^{10}$ Tramal - Cristália.
} 
esse período, promoveu-se a reversão das obstruções, tendo como acesso cirúrgico e protocolo os mesmos utilizados para promovê-las. Os drenos foram então removidos e as cavidades abdominais fechadas de acordo com a técnica descrita por TURNER \& MCILWRAITH (2002).

No pós-operatório foi instituída terapia antimicrobiana com penicilina benzatina ${ }^{11}$, na dose de $30.000 \mathrm{UI} \mathrm{k^{-1 }}$, IM, a cada $48 \mathrm{~h}$, perfazendo três aplicações. Como analgésico e anti-inflamatório, administrou-se flunixim meglumine ${ }^{12}$, na dose de $0,5 \mathrm{mg} \mathrm{kg}^{-1}$, IV, a cada $24 \mathrm{~h}$, durante dois dias. O curativo da ferida cirúrgica foi realizado com polivinilpirrolidona-iodo tópica a $1 \%$ duas vezes ao dia até a retirada dos pontos no décimo dia pósoperatório.

Para colheita do líquido peritoneal foi realizada a paracentese abdominal, segundo a técnica de WHITE (1990). Após a colheita, as amostras de líquido peritoneal e as de sangue, obtidas mediante punção da jugular, ambas colhidas em frascos estéreis sem anticoagulante, foram centrifugadas a $800 \mathrm{G}$ por cinco minutos e armazenadas a $-20^{\circ} \mathrm{C}$ até o momento das determinações. A concentração de fósforo inorgânico (método de Basques-Lustosa) e a atividade das enzimas CK, LDH, AST e FA foram obtidas com o auxílio de um conjunto de reagentes para diagnósticos ${ }^{13}$ e leituras espectrofotométricas ${ }^{14}$, utilizando-se método cinético. As amostras diluídas em fluoreto de sódio 1\% (1:2) foram utilizadas para a determinação da concentração de lactado, pelo método da lactato oxidase com analisador automático ${ }^{15}$

Para cada equino, as amostras de sangue e de líquido peritoneal foram colhidas uma hora antes do início do procedimento cirúrgico (T0), ao final do período de obstrução de três horas (T3ob) e 1, 3, 12, 24, 120 e 168 horas após a desobstrução (T1desT168des).

Para análise estatística, utilizou-se um delineamento inteiramente ao acaso, com quatro grupos submetidos a avaliações em oito momentos. Quando se constatou significância entre grupos e momentos, aplicou-se o teste de Tukey $(\mathrm{P}<0,05)$ para comparação das médias, por meio do programa estatístico SAS.

\section{RESULTADOS E DISCUSSÃO}

Os resultados da atividade sérica e do líquido peritoneal das enzimas CK, AST, FA e LDH e da

\footnotetext{
${ }^{11}$ Pentabiótico Veterinário Reforçado - Fort Dodge

${ }^{12}$ Flunixina Injetável - UCB S. A.

${ }^{13}$ Labtest - Sistema de Diagnósticos Ltda. - Lagoa Santa, Brazil.

${ }^{14}$ Labquest - Labtest.

${ }^{15}$ Lactímetro YSL 1500 Sport - Yelow Springs, Ohio, EUA.
}

concentração de fósforo e de lactato dos equinos dos grupos GI, GII, GIII e GIV estão apresentados nas Tabelas 1 e 2, respectivamente.

Nas três horas de obstrução (T3ob) não houve alterações nas concentrações de CK, AST, FA, LDH, fósforo inorgânico e de lactato no soro dos equinos avaliados. Após desobstrução (T3des, T12des e T24des), constatou-se, com exceção da FA, aumento sérico da CK, AST, LDH, lactato e de fósforo inorgânico nos animais dos grupos GII e GIII. Resultados semelhantes foram observados no líquido peritoneal dos animais dos referidos grupos (GII e GIII); entretanto, algumas alterações iniciaram-se já na fase de obstrução (CK, LDH, lactato e fósforo inorgânico) e perduraram durante a desobstrução (T1des-T120des). Os resultados foram associados à redução ou interrupção do fluxo sanguíneo intestinal que altera a permeabilidade da membrana celular e induz à degeneração das células intestinais, promovendo o aumento de variáveis bioquímicas nos fluidos orgânicos, como explicaram COTRAN et al. (1994), VALADÃO et al. (1996) e SOUTHWOOD (2006).

A fosfatase alcalina é uma enzima presente em muitos tecidos, principalmente ossos, mucosa intestinal e células renais tubulares. De acordo com PARRY \& BROWNLOW (1992) e VALENTE (2009), a mucosa do intestino delgado de muitas espécies de animais, incluindo os equinos, são extremamente ricas em FA, enquanto que a mucosa do intestino grosso possui pequena quantidade desta enzima. Tal fato faz com que a FA seja considerada específica para o diagnóstico de lesões localizadas no intestino delgado. Ademais, em ensaio realizado com coelhos, cães e humanos, DELANY et al. (1976) verificaram aumento na atividade de FA no líquido peritoneal após lesões no intestino delgado sem, contudo acarretar alterações na atividade sérica dessa enzima.

Tais afirmações concretizam os resultados expressos nas tabelas 1 e 2, onde constatam-se valores aumentados de FA unicamente no líquido peritoneal dos animais submetidos à obstrução do intestino delgado (GII e GIII). Entretanto, as alterações verificadas não auxiliaram na identificação do segmento intestinal obstruído, visto que ocorreram somente após a desobstrução. Esses resultados, acrescidos dos observados dentro de cada grupo, ao longo do período experimental, reforçam a afirmação de PARKS \& GRANGER (1986) e de MENDES et al. (2009) de que as lesões produzidas durante o período de obstrução evoluem com o retorno da perfusão. 
Tabela 1. Média e desvio-padrão da creatina quinase (U/L), aspartato aminotransferase (U/L), fosfatase alcalina (U/L), lactato desidrogenase $(\mathrm{U} / \mathrm{L})$, lactado $(\mathrm{mmol} / \mathrm{L})$ e de fósforo inorgânico $(\mathrm{mg} / \mathrm{dL})$ no soro de equinos do grupo-controle (GI) e de equinos submetidos à obstrução do duodeno (GII), do íleo (GIII) e do cólon maior (GIV), uma hora antes do procedimento cirúrgico (T0), ao final das três horas de obstrução (T3ob) e 1, 3, 12, 24, 72, 120 e 168 horas após a desobstrução (T1des-T168des)

Tempo (h)

Grupos

\begin{tabular}{|c|c|c|c|c|c|c|c|c|}
\hline & T0 & T3ob & T1des & T3des & T12des & T24des & T120des & T168des \\
\hline \multicolumn{9}{|c|}{ Creatina quinase } \\
\hline I & $340 \pm 142 \mathrm{Ab}$ & $503 \pm 172 \mathrm{Aa}$ & $493 \pm 102 \mathrm{Ab}$ & $403 \pm 99 \mathrm{Bb}$ & $750 \pm 131 \mathrm{Ba}$ & $633 \pm 102 \mathrm{Ba}$ & $226 \pm 124 \mathrm{Ab}$ & $210 \pm 119 \mathrm{Ab}$ \\
\hline II & $270 \pm 147 \mathrm{Ab}$ & $542 \pm 156 \mathrm{Aa}$ & $651 \pm 201 \mathrm{Aa}$ & $789 \pm 245 \mathrm{Aa}$ & $882 \pm 190 \mathrm{Ab}$ & $788 \pm 120 \mathrm{Aa}$ & $287 \pm 390 \mathrm{Ab}$ & $263 \pm 220 \mathrm{Ab}$ \\
\hline III & $307 \pm 112 \mathrm{Ab}$ & $539 \pm 204 \mathrm{Ab}$ & $614 \pm 237 \mathrm{Aa}$ & $886 \pm 382 \mathrm{Aa}$ & $1076 \pm 440 \mathrm{Aa}$ & $955 \pm 335 \mathrm{Aa}$ & $266 \pm 142 \mathrm{Ab}$ & $230 \pm 162 \mathrm{Ab}$ \\
\hline IV & $267 \pm 182 \mathrm{Ab}$ & $538 \pm 265 \mathrm{Aa}$ & $602 \pm 280 \mathrm{Aa}$ & $567 \pm 165 \mathrm{Ba}$ & $789 \pm 286 \mathrm{Ba}$ & $622 \pm 169 \mathrm{Ba}$ & $226 \pm 156 \mathrm{Ab}$ & $202 \pm 84 \mathrm{Ab}$ \\
\hline \multicolumn{9}{|c|}{ Aspartato aminotranferase } \\
\hline I & $241 \pm 60 \mathrm{Aa}$ & $237 \pm 26 \mathrm{Aa}$ & $217 \pm 47 \mathrm{Aa}$ & $237 \pm 51 \mathrm{Ba}$ & $325 \pm 63 \mathrm{Ba}$ & $311 \pm 43 \mathrm{Ba}$ & $267 \pm 57 \mathrm{Aa}$ & $256 \pm 52 \mathrm{Aa}$ \\
\hline II & $235 \pm 36 \mathrm{Ab}$ & $244 \pm 28 \mathrm{Ab}$ & $238 \pm 23 \mathrm{Ab}$ & $461 \pm 23 \mathrm{Aa}$ & $558 \pm 62 \mathrm{Aa}$ & $374 \pm 61 \mathrm{Aa}$ & $291 \pm 47 \mathrm{Aa}$ & $282 \pm 50 \mathrm{Aa}$ \\
\hline III & $239 \pm 61 \mathrm{Ab}$ & $255 \pm 51 \mathrm{Ab}$ & $257 \pm 72 \mathrm{Ab}$ & $470 \pm 51 \mathrm{Aa}$ & $456 \pm 18 \mathrm{ABa}$ & $482 \pm 15 \mathrm{Aa}$ & $330 \pm 73 \mathrm{Aa}$ & $321 \pm 79 \mathrm{Aa}$ \\
\hline IV & $258 \pm 26 \mathrm{Ab}$ & $267 \pm 38 \mathrm{Ab}$ & $253 \pm 51 \mathrm{Ab}$ & $281 \pm 34 \mathrm{Ba}$ & $371 \pm 45 \mathrm{Ba}$ & $360 \pm 40 \mathrm{Ba}$ & $314 \pm 37 \mathrm{Aa}$ & $275 \pm 43 \mathrm{Aa}$ \\
\hline \multicolumn{9}{|c|}{ Fosfatase Alcalina } \\
\hline I & $265 \pm 19$ Aa & $267 \pm 48 \mathrm{Aa}$ & $262 \pm 59 \mathrm{Aa}$ & $298 \pm 81 \mathrm{Aa}$ & $261 \pm 27 \mathrm{Aa}$ & $267 \pm 51 \mathrm{Aa}$ & $278 \pm 73 \mathrm{Aa}$ & $284 \pm 34 \mathrm{Aa}$ \\
\hline II & $278 \pm 46 \mathrm{Aa}$ & $266 \pm 62 \mathrm{Aa}$ & $243 \pm 52 \mathrm{Aa}$ & $251 \pm 59 \mathrm{Aa}$ & $343 \pm 22 \mathrm{Aa}$ & $269 \pm 81 \mathrm{Aa}$ & $252 \pm 56 \mathrm{Aa}$ & $244 \pm 51 \mathrm{Aa}$ \\
\hline III & $312 \pm 93 \mathrm{Aa}$ & $287 \pm 106 \mathrm{Aa}$ & $287 \pm 93 \mathrm{Aa}$ & $286 \pm 87 \mathrm{Aa}$ & $379 \pm 99 \mathrm{Aa}$ & $295 \pm 91 \mathrm{Aa}$ & $321 \pm 67 \mathrm{Aa}$ & $342 \pm 96 \mathrm{Aa}$ \\
\hline IV & $317 \pm 81 \mathrm{Aa}$ & $295 \pm 85 \mathrm{Aa}$ & $283 \pm 58 \mathrm{Aa}$ & $295 \pm 61 \mathrm{Aa}$ & $269 \pm 58 \mathrm{Aa}$ & $291 \pm 76 \mathrm{Aa}$ & $268 \pm 75 \mathrm{Aa}$ & $284 \pm 85 \mathrm{Aa}$ \\
\hline \multicolumn{9}{|c|}{ Lactato desidrogenase } \\
\hline I & $547 \pm 190 \mathrm{Ab}$ & $674 \pm 68 \mathrm{Aa}$ & $644 \pm 129 \mathrm{Aa}$ & $593 \pm 117 \mathrm{Ba}$ & $506 \pm 118 \mathrm{Bb}$ & $879 \pm 126 \mathrm{Ba}$ & $798 \pm 134 \mathrm{Aa}$ & $630 \pm 188 \mathrm{Aa}$ \\
\hline II & $568 \pm 127 \mathrm{Ab}$ & $730 \pm 264 \mathrm{Aa}$ & $695 \pm 174 \mathrm{Aa}$ & $744 \pm 225 \mathrm{Aa}$ & $836 \pm 253 \mathrm{Aa}$ & $1063 \pm 189 \mathrm{Aa}$ & $717 \pm 150 \mathrm{Aa}$ & $497 \pm 199 \mathrm{Ab}$ \\
\hline III & $581 \pm 192 \mathrm{Ab}$ & $695 \pm 165 \mathrm{Aa}$ & $720 \pm 265 \mathrm{Aa}$ & $655 \pm 140 \mathrm{Aa}$ & $693 \pm 238 \mathrm{ABa}$ & $998 \pm 289 \mathrm{ABa}$ & $866 \pm 227 \mathrm{Aa}$ & $763 \pm 251 \mathrm{Aa}$ \\
\hline IV & $557 \pm 205 \mathrm{Ab}$ & $749 \pm 197 \mathrm{Aa}$ & $728 \pm 250 \mathrm{Aa}$ & $600 \pm 195 \mathrm{ABb}$ & $614 \pm 277 \mathrm{ABb}$ & $855 \pm 289 \mathrm{Ba}$ & $728 \pm 226 \mathrm{Aa}$ & $647 \pm 217 \mathrm{Aa}$ \\
\hline \multicolumn{9}{|c|}{ Lactato } \\
\hline I & $1,00 \pm 0,42 \mathrm{Aa}$ & $0,72 \pm 0,59 \mathrm{Aa}$ & $1,16 \pm 0,52 \mathrm{Aa}$ & $0,10 \pm 0,00 \mathrm{Bb}$ & $0,80 \pm 0,53 \mathrm{Ba}$ & $0,10 \pm 0,00 \mathrm{Bb}$ & $0,63 \pm 0,43 \mathrm{Ab}$ & $0,68 \pm 0,67 \mathrm{Aa}$ \\
\hline II & $0,84 \pm 0,32 \mathrm{Aa}$ & $0,62 \pm 0,00 \mathrm{Ab}$ & $1,67 \pm 0,72 \mathrm{Aa}$ & $0,83 \pm 0,63 \mathrm{Aa}$ & $1,89 \pm 0,48 \mathrm{Aa}$ & $0,88 \pm 0,86 \mathrm{Aa}$ & $0,53 \pm 0,30 \mathrm{Ab}$ & $0,55 \pm 0,00 \mathrm{Ab}$ \\
\hline III & $0,82 \pm 0,32 \mathrm{Aa}$ & $0,56 \pm 0,34 \mathrm{Ab}$ & $1,13 \pm 0,32 \mathrm{Aa}$ & $0,76 \pm 0,39 \mathrm{Ab}$ & $1,20 \pm 0,34 \mathrm{ABa}$ & $0,73 \pm 0,50 \mathrm{ABb}$ & $0,75 \pm 0,62 \mathrm{Ab}$ & $0,51 \pm 0,52 \mathrm{Ab}$ \\
\hline IV & $0,83 \pm 0,28 \mathrm{Aa}$ & $0,58 \pm 0,44 \mathrm{Ab}$ & $0,87 \pm 0,31 \mathrm{Aa}$ & $0,23 \pm 0,60 \mathrm{Bb}$ & $0,83 \pm 0,63 \mathrm{Ba}$ & $0,23 \pm 0,59 \mathrm{ABb}$ & $0,71 \pm 0,56 \mathrm{Aa}$ & $0,53 \pm 0,40 \mathrm{Ab}$ \\
\hline \multicolumn{9}{|c|}{ Fósforo inorgânico } \\
\hline I & $3,16 \pm 2,06 \mathrm{Ab}$ & $3,73 \pm 1,73 \mathrm{Aa}$ & $3,80 \pm 1,08 \mathrm{Aa}$ & $3,66 \pm 1,45 \mathrm{Ba}$ & $3,63 \pm 1,61 \mathrm{Ba}$ & $3,20 \pm 1,82 \mathrm{Bb}$ & 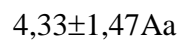 & $3,36 \pm 0,76 \mathrm{Ab}$ \\
\hline II & $4,03 \pm 1,03 \mathrm{Ab}$ & $4,46 \pm 1,31 \mathrm{Aa}$ & $4,83 \pm 0,73 \mathrm{Aa}$ & $4,95 \pm 0,89 \mathrm{Aa}$ & $4,85 \pm 1,02 \mathrm{Aa}$ & $4,11 \pm 0,61 \mathrm{Aa}$ & $3,30 \pm 0,71 \mathrm{Ab}$ & $4,03 \pm 0,67 \mathrm{Ab}$ \\
\hline III & $3,90 \pm 0,81 \mathrm{Aa}$ & $3,91 \pm 0,21 \mathrm{Aa}$ & $4,30 \pm 0,89 \mathrm{Aa}$ & $3,95 \pm 0,91 \mathrm{ABa}$ & $4,26 \pm 0,77 \mathrm{ABa}$ & $4,30 \pm 0,71 \mathrm{ABa}$ & $4,03 \pm 0,82 \mathrm{Aa}$ & $3,48 \pm 0,68 \mathrm{bA}$ \\
\hline IV & $4,15 \pm 1,49 \mathrm{Aa}$ & $4,35 \pm 1,00 \mathrm{Aa}$ & $4,86 \pm 2,09 \mathrm{Aa}$ & $3,63 \pm 1,71 \mathrm{Bb}$ & $3,98 \pm 1,53 \mathrm{Ba}$ & $3,20 \pm 1,20 \mathrm{Bb}$ & $4,96 \pm 1,78 \mathrm{Aa}$ & $3,73 \pm 0,84 \mathrm{Ab}$ \\
\hline
\end{tabular}

Letras maiúsculas distintas, nas colunas, indicam diferenças significativas entre os grupos $(\mathrm{P}<0,05)$.

Letras minúsculas distintas, nas linhas, indicam diferenças significativas entre os momentos $(\mathrm{P}<0,05)$. 
Tabela 2. Média e desvio-padrão de creatina quinase (U/L), aspartato aminotransferase (U/L), lactato desidrogenase (U/L), lactado $(\mathrm{mmol} / \mathrm{L})$ e de fósforo inorgânico $(\mathrm{mg} / \mathrm{dL})$ no líquido peritoneal de equinos do grupo-controle (GI) e de equinos submetidos à obstrução do duodeno (GII), íleo (GIII) e de cólon maior (GIV), uma hora antes do procedimento cirúrgico (T0), ao final das três horas de obstrução (T3ob) e 1, 3, 12, 24, 72, 120 e 168 horas após a desobstrução (T1des-T168des)

Tempo (h)

Grupos

\begin{tabular}{|c|c|c|c|c|c|c|c|c|}
\hline & T0 & T3ob & T1des & T3des & T12des & T24des & T120des & T168des \\
\hline \multicolumn{9}{|c|}{ Creatina quinase } \\
\hline I & $49 \pm 37 \mathrm{Aa}$ & $48 \pm 21 \mathrm{Ba}$ & $56 \pm 25 \mathrm{Ba}$ & $48 \pm 21 \mathrm{Ba}$ & $72 \pm 43 \mathrm{Ba}$ & $104 \pm 854 \mathrm{Ba}$ & $96 \pm 21 \mathrm{Aa}$ & $75 \pm 31 \mathrm{Aa}$ \\
\hline II & $36 \pm 20 \mathrm{Abc}$ & $461 \pm 766 \mathrm{Ab}$ & $1449 \pm 1689$ Aa & $2148 \pm 2172 \mathrm{Aa}$ & $3157 \pm 2046 \mathrm{Aa}$ & $3792 \pm 1384 \mathrm{Aa}$ & $178 \pm 85 \mathrm{Ab}$ & $110 \pm 61 \mathrm{Ab}$ \\
\hline III & $32 \pm 12 \mathrm{Abc}$ & $858 \pm 1568 \mathrm{Aa}$ & $1866 \pm 2729 \mathrm{Aa}$ & $1922 \pm 2729$ Aa & $1659 \pm 2053 \mathrm{Aa}$ & $3679 \pm 1752 \mathrm{Aa}$ & $113 \pm 39 \mathrm{Ab}$ & $139 \pm 146 \mathrm{Ab}$ \\
\hline IV & $40 \pm 19 \mathrm{Aa}$ & $156 \pm 78 \mathrm{Ba}$ & $124 \pm 105 \mathrm{Ba}$ & $96 \pm 113 \mathrm{Ba}$ & $93 \pm 119 \mathrm{Ba}$ & $106 \pm 81 \mathrm{Ba}$ & $153 \pm 94 \mathrm{Aa}$ & $80 \pm 53 \mathrm{Aa}$ \\
\hline \multicolumn{9}{|c|}{ Aspartato aminotranferase } \\
\hline I & $40 \pm 4 \mathrm{Ab}$ & $111 \pm 45 \mathrm{Ab}$ & $124 \pm 62 \mathrm{Ab}$ & $133 \pm 70 \mathrm{Ba}$ & $150 \pm 92 \mathrm{Ba}$ & $163 \pm 36 \mathrm{Ba}$ & $141 \pm 44 \mathrm{Aa}$ & $132 \pm 39 \mathrm{Aa}$ \\
\hline II & $43 \pm 25 \mathrm{Ab}$ & $131 \pm 50 \mathrm{Ab}$ & $170 \pm 49$ Aа & $247 \pm 94 \mathrm{Aa}$ & $248 \pm 71 \mathrm{Aa}$ & $309 \pm 86 \mathrm{Aa}$ & $161 \pm 43 \mathrm{Aa}$ & $172 \pm 45 \mathrm{Aa}$ \\
\hline III & $46 \pm 22 \mathrm{Ab}$ & $133 \pm 49 \mathrm{Ab}$ & $175 \pm 133 \mathrm{Ab}$ & $244 \pm 172 \mathrm{Aa}$ & $258 \pm 173 \mathrm{Aa}$ & $360 \pm 136 \mathrm{Aa}$ & $210 \pm 37 \mathrm{Aa}$ & $179 \pm 47 \mathrm{Aa}$ \\
\hline IV & $53 \pm 27 \mathrm{Ab}$ & $122 \pm 51 \mathrm{Ab}$ & $176 \pm 57 \mathrm{Aa}$ & $173 \pm 47 \mathrm{Ba}$ & $209 \pm 73 \mathrm{ABa}$ & $166 \pm 42 \mathrm{ABa}$ & $209 \pm 60 \mathrm{Aa}$ & $152 \pm 6 \mathrm{Aa}$ \\
\hline \multicolumn{9}{|c|}{ Fosfatase Alcalina } \\
\hline I & $28 \pm 11 \mathrm{Abc}$ & $80 \pm 48 \mathrm{Abc}$ & $113 \pm 45 \mathrm{Ab}$ & $232 \pm 92 \mathrm{Bb}$ & $1847 \pm 2340 \mathrm{Ba}$ & $1318 \pm 1654 \mathrm{Ba}$ & $1158 \pm 1689 \mathrm{Ba}$ & $1329 \pm 1243 \mathrm{Aa}$ \\
\hline II & $34 \pm 22 \mathrm{Abc}$ & $135 \pm 70 \mathrm{Abc}$ & $230 \pm 94 \mathrm{Abc}$ & $500 \pm 766 \mathrm{Ab}$ & $2827 \pm 2207 \mathrm{Aa}$ & $2269 \pm 2176 \mathrm{Aa}$ & $1824 \pm 2776 \mathrm{Aa}$ & $890 \pm 1193 \mathrm{Aa}$ \\
\hline III & $29 \pm 12 \mathrm{Abc}$ & $168 \pm 37 \mathrm{Ab}$ & $254 \pm 100 \mathrm{Ab}$ & $369 \pm 136 \mathrm{Ab}$ & $2408 \pm 2172 \mathrm{Aa}$ & $2019 \pm 2009 \mathrm{Aa}$ & $1678 \pm 2030 \mathrm{Aa}$ & $1106 \pm 1709 \mathrm{Aa}$ \\
\hline IV & $32 \pm 32 \mathrm{Ab}$ & $164 \pm 42 \mathrm{Ab}$ & $222 \pm 136 \mathrm{Ab}$ & $290 \pm 755 \mathrm{ABb}$ & $1880 \pm 2772 \mathrm{Ba}$ & $1272 \pm 1134 \mathrm{Ba}$ & $1557 \pm 811 \mathrm{ABa}$ & $1166 \pm 1123 \mathrm{Aa}$ \\
\hline \multicolumn{9}{|c|}{ Lactato desidrogenase } \\
\hline I & $58 \pm 38 \mathrm{Ab}$ & $1038 \pm 334 \mathrm{Ba}$ & $1057 \pm 387 \mathrm{Ba}$ & $1159 \pm 521 \mathrm{Ba}$ & $1289 \pm 544 \mathrm{Ba}$ & $1618 \pm 225 \mathrm{Ba}$ & $1198 \pm 471 \mathrm{Ba}$ & $1068 \pm 531 \mathrm{Aa}$ \\
\hline II & $63 \pm 58 \mathrm{Ab}$ & $1314 \pm 371 \mathrm{Aa}$ & $1843 \pm 485 \mathrm{Aa}$ & $2010 \pm 564 \mathrm{Aa}$ & $2191 \pm 626 \mathrm{Aa}$ & $2838 \pm 498 \mathrm{Aa}$ & $1770 \pm 1326 \mathrm{Aa}$ & $1126 \pm 532 \mathrm{Aa}$ \\
\hline III & $69 \pm 48 \mathrm{Ab}$ & $1503 \pm 795 \mathrm{Aa}$ & $1600 \pm 703 \mathrm{ABa}$ & $1686 \pm 641 \mathrm{ABa}$ & $1748 \pm 796 \mathrm{ABa}$ & $2237 \pm 397 \mathrm{ABa}$ & $1514 \pm 220 \mathrm{ABa}$ & $912 \pm 191 \mathrm{Aa}$ \\
\hline IV & $68 \pm 95 \mathrm{Ab}$ & $1016 \pm 506 \mathrm{Ba}$ & $1016 \pm 609 \mathrm{Ba}$ & $1054 \pm 626 \mathrm{Ba}$ & $1113 \pm 749 \mathrm{Ba}$ & $1859 \pm 391 \mathrm{Ba}$ & $1043 \pm 1400 \mathrm{Ba}$ & $844 \pm 243 \mathrm{Aa}$ \\
\hline \multicolumn{9}{|c|}{ Lactato } \\
\hline I & $0,27 \pm 0,35 \mathrm{Ab}$ & $0,62 \pm 1,07 \mathrm{Ba}$ & $0,61 \pm 1,37 \mathrm{Ba}$ & $0,52 \pm 2,02 \mathrm{Ba}$ & $0,61 \pm 1,68 \mathrm{Ba}$ & $0,58 \pm 2,31 \mathrm{Ba}$ & $0,70 \pm 2,92 \mathrm{Aa}$ & $0,54 \pm 3,28 \mathrm{Aa}$ \\
\hline II & $0,32 \pm 0,58 \mathrm{Ab}$ & $0,88 \pm 1,12 \mathrm{Aa}$ & $1,33 \pm 1,29 \mathrm{Aa}$ & $1,27 \pm 1,84 \mathrm{Aa}$ & 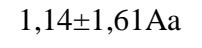 & $1,05 \pm 2,18 \mathrm{Aa}$ & $0,60 \pm 2,96 \mathrm{Aa}$ & $0,53 \pm 3,30 \mathrm{Aa}$ \\
\hline III & $0,25 \pm 0,87 \mathrm{Ab}$ & $0,98 \pm 1,26 \mathrm{Aa}$ & $0,87 \pm 1,43 \mathrm{ABa}$ & $0,98 \pm 2,02 \mathrm{Aa}$ & $0,96 \pm 1,70 \mathrm{ABa}$ & $0,85 \pm 2,30 \mathrm{ABa}$ & $0,55 \pm 2,98 \mathrm{Aa}$ & $0,48 \pm 3,31 \mathrm{Aa}$ \\
\hline IV & $0,19 \pm 1,20 \mathrm{Ab}$ & $0,46 \pm 1,47 \mathrm{Bb}$ & $0,70 \pm 1,61 \mathrm{Ba}$ & $0,84 \pm 2,07 \mathrm{ABa}$ & $0,81 \pm 1,81 \mathrm{ABa}$ & $0,61 \pm 2,46 \mathrm{Ba}$ & $0,62 \pm 3,02 \mathrm{Aa}$ & $0,42 \pm 3,37 \mathrm{Ab}$ \\
\hline \multicolumn{9}{|c|}{ Fósforo inorgânico } \\
\hline I & $1,96 \pm 0,64 \mathrm{Aa}$ & $1,93 \pm 0,72 \mathrm{Ba}$ & $2,36 \pm 0,89 \mathrm{Ba}$ & $2,86 \pm 0,65 \mathrm{Ba}$ & $2,60 \pm 1,58 \mathrm{Ba}$ & $2,93 \pm 0,73 \mathrm{Ba}$ & $2,53 \pm 0,74 \mathrm{Ba}$ & $3,06 \pm 0,98 \mathrm{Aa}$ \\
\hline II & $2,70 \pm 0,70 \mathrm{Ab}$ & $4,30 \pm 1,32 \mathrm{Aa}$ & $5,11 \pm 1,31 \mathrm{Aa}$ & $4,88 \pm 0,83 \mathrm{Aa}$ & $4,88 \pm 1,00 \mathrm{Aa}$ & $4,71 \pm 0,86 \mathrm{Aa}$ & $4,48 \pm 0,71 \mathrm{Aa}$ & $4,68 \pm 0,92 \mathrm{Aa}$ \\
\hline III & $2,15 \pm 0,61 \mathrm{Ab}$ & $4,08 \pm 0,98 \mathrm{Aa}$ & $4,88 \pm 1,06 \mathrm{Aa}$ & $4,48 \pm 0,74 \mathrm{ABa}$ & $4,58 \pm 0,79 \mathrm{Ba}$ & $3,43 \pm 0,62 \mathrm{ABa}$ & $3,86 \pm 1,09 \mathrm{ABa}$ & $3,73 \pm 0,63 \mathrm{Aa}$ \\
\hline IV & $2,10 \pm 1,57 \mathrm{Ab}$ & $2,96 \pm 1,30 \mathrm{ABa}$ & $3,45 \pm 1,98 \mathrm{ABa}$ & $3,20 \pm 1,43 \mathrm{Ba}$ & $3,26 \pm 1,28 \mathrm{Ba}$ & $2,95 \pm 1,30 \mathrm{Ba}$ & $2,43 \pm 1,14 \mathrm{Ba}$ & $3,10 \pm 1,55 \mathrm{Aa}$ \\
\hline
\end{tabular}

Letras maiúsculas distintas, nas colunas, indicam diferenças significativas entre os grupos $(\mathrm{P}<0,05)$.

Letras minúsculas distintas, nas linhas, indicam diferenças significativas entre os momentos $(\mathrm{P}<0,05)$. 
Aumento na concentração de FA no líquido peritoneal também foram observados por VALADÃO et al. (2004) em equinos submetidos à punção cecal percutânea. Segundo FROSCHER \& NAGODE (1981), o aumento de FA no líquido peritoneal de equinos com cólica somente pode ser utilizado como indicativo de lesão intestinal em distúrbios com no máximo 1 ou 2 horas de evolução. Após esse período, o aumento de FA no líquido peritoneal deve-se à degranulação ou morte de granolócitos e não à lesão intestinal propriamente dita. O aumento na contagem de neutrófilos no líquido peritoneal de equinos durante a evolução da síndrome cólica é achado comum, visto que essas células são as efetoras fundamentais na defesa do organismo contra infecções bacterianas, fagocitando microorganismos, células mortas e debris celulares. Corroborando essas afirmações, leucocitose por neutrofilia foi observada no líquido peritoneal dos animais do GII e do GIII, após desobstrução, ou seja, nos mesmos momentos em que houve aumento na atividade da FA no líquido peritoneal.

Nas tabelas 1 e 2, constatam-se valores aumentados de fósforo no soro e no líquido peritoneal dos animais dos grupos GII e GIII. Entretanto, as alterações observadas no líquido peritoneal ocorreram desde a fase de obstrução. Segundo VALADÃO et al. (1996), as diferenças entre a cinética das alterações séricas e peritoneais de fósforo residem no fato de que o fósforo, presente em altas concentrações nas células intestinais, é permeado inicialmente das células intestinais isquêmicas para o lume intestinal e cavidade peritoneal $\mathrm{e}$, posteriormente, carreado para a circulação sistêmica através do sistema de drenagem linfática ou circulação portal. Comentários semelhantes são válidos para as demais variáveis bioquímicas analisadas e que apresentaram aumento peritoneal anterior ao sérico.

Aumento na concentração sérica e peritoneal de fósforo também foi observado por LIAO et al. (1995) e MOORE et al. (1998). Segundo ARDEN \& STICK (1988), concentrações de fósforo no líquido peritoneal acima de 3,6mmol/L indicam necessidade de ressecção intestinal ou eutanásia, com $77 \%$ e $76 \%$ de sensibilidade e especificidade, respectivamente. Neste experimento, com exceção do momento que antecedeu o procedimento de obstrução intestinal (T0), concentrações de fósforo superiores a $3,6 \mathrm{mmol} / \mathrm{L}$ foram constantes até mesmo entre os animais do grupo controle/instrumentado (GI). Desse modo, são necessários critérios para utilização isolada dessa variável nas indicações descritas por ARDEN \& STICK (1988), pois, além da ressecção intestinal não ter sido necessária, nenhum dos animais foi a óbito. Diferenças como essas podem advir de diferenças existentes entre técnicas laboratoriais para a determinação da concentração de fósforo inorgânico, como explicaram MOORE et al. (1998).

O lactato, gerado em condições de deficiência de oxigênio pelo músculo esquelético, eritrócitos, cérebro e intestino, pode ser utilizado segundo SOUTHWOOD (2006), na indicação da severidade da afecção, no direcionamento da terapia e na elaboração do prognóstico. Neste ensaio, após a desobstrução (T3des, T12des e T24des), constatouse aumento dos valores do lactato no soro dos animais do GII e GIII. Concomitante ao aumento sérico de lactato apresentado pelos animais do GII e GIII, alterações também foram observadas no líquido peritoneal desses animais ainda durante a fase de obstrução. Entretanto, os valores não ultrapassaram $2 \mathrm{mmol} / \mathrm{L}$, limite considerado normal por CÂMARA \& SILVA et al. (2007). Resultados semelhantes foram obtidos por DATT \& USENIK (1975) em equinos submetidos à obstrução experimental de duodeno e íleo. Segundo os autores, os resultados deveram-se à maior pressão intraluminal sofrida pela alça intestinal em função do diâmetro reduzido destas quando comparadas a segmentos do intestino grosso. Entretanto, segundo HAJI-MICHAEL et al. (1999) e KANEKO et al. (2008), as células inflamatórias, especialmente os neutrófilos, também podem ser os responsáveis pelo aumento de lactato no foco inflamatório, visto que $80 \%$ de toda glicose metabolizada por essas células é convertida em lactato e, como mencionado anteriormente, verificou-se leucocitose por neutrofilia no líquido peritoneal dos animais do GII e GIII, porém, apenas após a desobstrução.

Comentários semelhantes são válidos para a variável LDH que catalisa a reação reversível de Llactato em piruvato. Entretanto, segundo CHANEY et al. (2004), dentre as enzimas frequentemente utilizadas na avaliação da perfusão tecidual, a CK, que, em condições de anaerobiose celular, catalisa a fosforilação da adenosina difosfato (ADP) do fosfato de creatina, tornando o adenosina trifosfato (ATP) disponível para a contração muscular, é considerada mais específica além de ser menos afetada pela contaminação sanguínea da amostra.

Aumento na atividade sérica e peritoneal de CK e de AST foi verificado nos animais dos grupos GII e GIII. À semelhança do observado para as variáveis LDH, fósforo inorgânico e lactado, as alterações no líquido peritoneal ocorreram de forma mais precoce, mecanismo já explicado anteriormente. Valores aumentados de CK também foram obtidos por MOORE et al. (1998) em equinos submetidos à isquemia e reperfusão do cólon maior e, para esses autores, as alterações deveram-se à 
exteriorização e manipulação intestinal. Para SVENDSEN et al. (1979) e DI FILIPPO \& SANTANA (2009), as alterações foram associadas à injúria intestinal. A origem do aumento da CK somente poderia ser determinada quando simultaneamente suas isoenzimas fossem avaliadas (MOORE et al., 1998). Entretanto, a ausência de alterações significativas na atividade sérica e peritoneal de $\mathrm{CK}$, entre momentos, apresentados pelos animais do GI (controle/instrumentado) corrobora a afirmação de que os resultados deveramse à lesão intestinal decorrente do modelo de obstrução.

\section{CONCLUSÕES}

Equinos submetidos à obstrução do duodeno e íleo apresentam aumento nas concentrações séricas e peritoneais de lactato, fósforo inorgânico e na atividade das enzimas CK, LDH, AST e FA. Entretanto, após período de três horas de obstrução só foram observadas alterações nas concentrações peritoneais de lactato, $\mathrm{LDH}, \mathrm{CK}$ e de fósforo inorgânico. Os resultados foram associados à lesão entérica desencadeada pelo modelo de obstrução e revelaram que a análise bioquímica do líquido peritoneal, quando comparada à sérica, permite o diagnóstico precoce de alterações intestinais, devendo ser priorizada na avaliação pré-operatória do equino com cólica.

\section{AGRADECIMENTO}

À Fundação de Amparo à Pesquisa do Estado de São Paulo (Fapesp) pelo financiamento integral a esta pesquisa (processos $\mathrm{n}^{\mathrm{0}} 05 / 58712-0$ e 06/55377-8).

\section{COMITÊ DE ÉTICA E BIOSSEGURANÇA}

Aprovado pela Comissão de Ética e Bem Estar Animal (CEBEA), protocolo nº23232-05.

\section{REFERÊNCIAS}

ARDEN, W.A.; STICK, J.A. Serum and peritoneal fluid phosphate concentrations as predictors of major intestinal injury with equine colic. Journal American Veterinary Medical Association, v.193, n.8, p.927-930, 1988.

CÂMARA E SILVA, I.A.; DIAS, R.V.C.; SOTOBLANCO, B. Determinação das atividades séricas de creatina quinase, lactato desidrogenase e aspartato aminotransferase em eqüinos de diferentes categorias de atividade. Arquivo Brasileiro de Medicina Veterinária e Zootecnia, v.59, n.1, p.250-252, 2007.

CHANEY, K.; MACLEAY, J.M.; ENNS, R.M.;
ALSOBAYIL, F.; KAWCEK, C.; FRISBIE, D. Effects of induced lameness via carpal osteochondral fragmentation on plasma creatine kinase activity in horses. Journal of Equine Veterinary Science, v.24, n.12, p. 531-534, 2004.

COTRAN, R.S.; KUMAR, V.; ROBBINS, S.L. Robbins pathologic basis of disease. 5. ed. Philadelphia: Saunders, 1994. Cellular injury and cellular death: p.1-34.

DATT, S.C.; USENIK, E.A. Intestinal obstruction in the horse, Physical signs and blood chemistry. Cornell Veterinarian, v.65, n.2, p.152-172, 1975.

DELANY, H.M.; MOSS, D.M. CARNEVALE, N. The use of enzyme analysis of peritoneal blood in the clinical assessment of abdominal organ injury. Surgery Gynecology Obstetrics, v.142, p.161-167, 1976.

DI FILIPPO, P.A.; PEREIRA, R.N.; PEROTTA, J.H.; ALVES, A.E.; DIAS, D.P.M.; SANTANA, A.E. Estudo retrospectivo de 50 casos de cólica em equinos atendidos no hospital veterinário da FCAV - UNESP, no período de setembro de 2004 a julho de 2005. Ciência Animal Brasileira, v.11, n.3, p. 689-694, 2010.

DI FILIPPO, P.A.; SANTANAI, A.E.; SEUDO LOPES, M.C.; PEROTTA, J.H.; PEREIRA, R.N.; PEREIRA, G.T. Hemogasometria de eqüinos submetidos à obstrução experimental do duodeno, íleo e cólon maior. Ciência Rural, v.39, n.1, p.156-162, 2009.

FROSCHER, B.G.; NAGODE, L.A. Origin and importance of increased alkaline phosphatase activity in peritoneal fluids of horses with colic. American Journal Veterinary Research, v.42, n.5, p.888-891, 1981.

HAJI-MICHAEL, P.G.; LADRIERE, L.; SENER, A. et al. Leukocyte glycolysis and lactate output in animal sepsis and ex human blood. Metabolism, v.48, n.6, p.779785, 1999.

KANEENE, J. B.; MILLER, R.; ROSS, W. A.; GALLAGHER, K.; MARTENIUK, J.; ROOK, J. Risk factors for colic in Michigan (USA) equine population. Preventive Veterinary Medicine, v. 30, p. 23-36, 1997.

KANEKO, J.J.; HARVEY, J.W.; BRUSS, M. Clinical biochemistry of domestic animals. San Diego: Academia Press, 2008. p.117-139.

LIAO, X.P.; SHE, Y.X.; SHI, C.R.; LI, M. Changes in body fluid markers in intestinal ischemia. Journal of Pediatric Surgery, v.30, n.10, p.1412-1415, 1995.

MENDES, H.M.F.; FALEIROS, R.R.; VASCONCELOS, A.C.; ALVES, G.E.S.; MOORE, R.M. Apoptose no cólon menor eqüino submetido à isquemia e reperfusão experimentais. Pesquisa Veterinária Brasileira. v. 29, n.3, p. 198-204, 2009.

MOORE, R.M.; MUIR, W.W.; RUSH, B.R. Systemic and colonic venous plasma biochemical alterations in horses during low-flow ischemia and reperfusion of the large colon. Canadian Journal Veterinary Research, v. 62, p.14-20, 1998.

PARKS, D.A.; GRANGER, D.N. Contribuitions of 
ischemia and reperfusion to mucosal lesion formation. The American Journal of Physiology, v.250, p.G749G753, 1986.

PARRY, B.W.; BROWNLOW, M.A. Peritoneal fluid. In: ROBINSON, N.E. Cytology and hematology of the horse. California : American Veterinary, 1992. p.121-151.

SAS Intitute. System for Information. Versão 8. Sas Institute: Cary, NC, 2000. Software.

SOUTHWOOD, L. Acute abdomen. Clinical Techniques in Equine Practice, v. 5, n. 2, p. 112-126. 2006.

SVENDSEN, C.K.; HJORTKJAER, R.K.; HESSELHOLT, M. Colic in the horse: a clinical and clinical chemical study of 42 cases. Nordisk Veterinaermedicin, v.31, n.10, p.1-32, 1979.

THOEFNER, M. B.; THOEFNER, M. B.; ERSBOLL, B. K.; JANSSON, N.; HESSEL HOLT, M. Diagnostic decision rule for support in clinical assessment of the need for surgical intervention in horses with acute abdominal pain. Canadian Journal Veterinary Research, v. 67, n. 1, p. 20-29, 2003.

TURNER, A.S.; McILWRAITH, C.W. Laparotomia do flanco e exploração abdominal. In: Técnicas cirúrgicas em animais de grande porte, São Paulo: Roca, 2002, p.237-242.

VALADÃO, C.A.A.; ÁVILA JÚNIOR, O.S.; CAMPOS FILHO, E. Aspectos bioquímicos do plasma e fluido peritoneal de eqüinos com cólica. Brazilian Journal of Veterinary Research Animal Science, v. 33, n. 1, p. 3235, 1996.

VALADÃO, C.A.A.; PUELKER, R.Z.; SOUZA, A.H. Cracterísticas do líquido peritoneal de equiinos normais após punção cecal percutânea. Ciência Rural, v.34, n.6, p.1817-1820, 2004

VALENTE, P. P.; CATTELAN, J. W.; SANTANA, A. E.; MALHEIROS, E. B.; DUARTE, C. A.; RASERA, L.; AITA, A. C. Concentrações de fibrinogênio plasmático, fosfatase alcalina sérica e do fibrinogênio e fosfatase alcalina no fluido peritoneal de equinos submetidos à enterorrafias aposicional e invaginante no cólon descendente. Nucleus Animalium, v.1, n.2, p. 95-106, 2009.

WHITE, N.A. Epidemiology and etiology of colic. In: WHITE, N.A. (Ed). The equine acute abdomen. Philadelphia : Lea \& Febiger, 1990. p.49-64. 